\title{
Exploration of the Effect of a Daily Structured Physical Activity Programme on Secondary School Students' Body Measurements and Attitudes
}

\author{
Professor Valerie Stoute ${ }^{1}$, Nicole Camille Parris, ${ }^{2, *}$, Euclid Nicholas-Sammy ${ }^{3}$ \\ ${ }^{1}$ Environmental and Postgraduate Studies and Research, The University of Trinidad and Tobago, Arima, Trinidad and Tobago \\ ${ }^{2}$ Science Department, Ministry of Education, Port of Spain, Trinidad and Tobago \\ ${ }^{3}$ Curriculum Division, Ministry of Education, Port of Spain, Trinidad and Tobago \\ *Corresponding author: nicoleparris2014@gmail.com
}

Received February 17, 2019; Revised April 09, 2019; Accepted May 04, 2019

\begin{abstract}
This study explores the potential of a structured programme of daily physical activity to have a beneficial effect on students' attitudes and body measurements. An action research study was conducted at a coeducational school with a sample of 21 students aged from 13 to 15 years. It was carried out during the lunch period for 30 minutes or more each session over a six-week period for three days per week. The students were measured (height, weight, waist, hip, chest, BMI, and \% body fat) at the beginning and at the end of the programme. They were also surveyed, at the beginning, on their then current patterns of engagement in physical activity and on their views on the importance of physical education in maintaining a healthy lifestyle. At the end of the programme, they were surveyed again on what they perceived as the benefits and disadvantages of the programme. In addition to the surveys, Observations and Field notes were used. Statistical Data Analysis was carried out using SPSS V.22. The significance of any changes over the course of the programme in weight, waist measurement, hip measurement, \% body fat, or BMI was estimated using a Repeated Measures General Linear Model (GLM) analysis with sex as the independent variable and with the students' initial heights and ages as covariates. There was no statistically significant difference in any of the biometric measurements, although there were downward trends in waist (for girls) and hip (for boys) measurements, BMI, and \% body fat. Participants held positive views of the programme and of its benefits to them with $95 \%$ indicating that the programme should be repeated. The researchers' observations and field notes supported the students reported positive responses since it was noted that students improved in fitness and enjoyed the activity throughout the programme.
\end{abstract}

Keywords: action research, structured physical activity, Repeated Measures statistical design, biometric measurements

Cite This Article: Professor Valerie Stoute, Nicole Camille Parris, and Euclid Nicholas-Sammy, "Exploration of the Effect of a Daily Structured Physical Activity Programme on Secondary School Students' Body Measurements and Attitudes." Journal of Physical Activity Research, vol. 4, no. 2 (2019): 80-89. doi: 10.12691/jpar-4-2-1.

\section{Introduction}

This study explores the potential of a structured programme of daily physical activity to have a beneficial effect on students' attitudes and body measurements. An action research project was conducted at a co-educational secondary school in Trinidad and Tobago. There is a lack of participation in physical activities during school hours and not enough time in the current syllabus to encourage the students to engage in a healthy lifestyle. Many of these 21 st century digital students are exposed to myriad technological devices which are attracting them away from physical activity. Within recent times, personal observation has shown that students' attitudes to physical education, especially the practical aspect, have changed and continue to deteriorate further as they become more interested in getting notes for examinations and less in practicing healthy habits, showing increasing evidence of sedentary lifestyles. This change has negatively affected the level of participation in physical activity during school hours.

\subsection{Research Questions}

1. To what extent does a daily structured physical activity change participating students' attitudes towards Physical Education?

2. To what extent does a daily structured physical activity affect participating students' weights and body measurements? 


\subsection{Significance of the Study}

The purpose of this study is to explore the impact of a daily structured Physical Activity Programme on students' body weights and their attitudes to physical activity. It is believed that the implementation of such a programme will encourage students to increase and improve their participation in physical activities during school hours and create a desire in them to continue throughout their adulthood to stay physically active. If so, this should lead to healthy lifestyle changes and, at the same time, good weight management.

This study illustrates that physical activity has the potential to impact positively on students to become change agents, make wise decisions about their lifestyle changes, and develop critical thinking skills as stated in a 2011 World Health Organisation report [16]. The study could provide evidence to support a more frequent use of daily activities in the Physical Education practical classes as a means of controlling weight gain. The intent is to provide stakeholders, through the implementation of a daily structured physical activity programme, with tangible evidence that physical activity is an inexpensive and effective path to effecting attitudinal change and managing weight, both of which should lead, all other things being the same, to a more healthy lifestyle.

There is the possibility that this could have additional benefits of fostering better relationships between students and teachers, perhaps decreasing indiscipline in students, and providing a more salubrious atmosphere for educators.

\section{Background Literature}

Even though physical activity is universally acknowledged to be an important part of healthy functioning and wellbeing, the full scope of its value is rarely appreciated [2]. Without regular physical activity the body slowly loses its strength, stamina, and ability to function well. Individuals, who are physically active and are at a healthy weight, live about seven years longer than those who are not active and are obese [1].

Physical activity is associated with longer life expectancy even at relatively low levels, as reported by the National Cancer Institute [9]. Regular activity was found to be beneficial regardless of a person's body weight, according to a study by a team of researchers who are a part of the National Institute of Health. They found that people who engaged in leisure-time physical activity had life expectancy gains of four or more years compared with those who were inactive [9]. Similarly, it has been suggested that 150 minutes of physical activity per week enhances fitness [1]. According to the report, this could be achieved by 30 minutes of activity 5 days a week (something which is possible during school hours, incidentally).

There have been several studies which have reported on the importance of regular physical activity for weight control. According to Wing et al. [15], to effectively reduce body weight, it is widely accepted that a negative energy condition needs to be present, whereby energy absorbed in the form of calories is less than that expended through activity. On the other hand to maintain weight loss or to prevent weight gain, energy intake must balance the outflow. Thus, physical activity can be an important intervention to achieve desired body-weight regulation. However, the effect of physical activity alone on reductions in body weight may be somewhat modest but can be more effective cumulatively on a long-term basis [15].

Several studies have shown that a sedentary lifestyle not only affects body weight but also reduces physical performance. Overweight and obesity are thus negatively correlated with physical activity, as assessed through standardized tests [14]. Increasing the level of participation in physical activity among overweight, obese and, particularly, low-active individuals should contribute to improved health and quality of life into adulthood. Ultimately, a healthier adult population should lower the economic burden on the public health system from diseases associated with obesity and physical inactivity [10].

Managing a healthy lifestyle is a learned behavior, as is posited in social cognitive theory [3]. In this article, Bandura proposes that behavior is based on environmental (learned) influences, on personal factors, with selfefficacy being a central tenet, and on the attributes of the behavior itself. Young people should be taught how to manage their physical health up to the point when enough time has elapsed for them to learn how to make it a lifestyle. Implementing a daily structured physical activity programme can help in this regard. There is some evidence to suggest that regular physical activity behavior, established early in the life of children, track into adulthood, according to Mc Kenzie and Lounsbery [8]. However, for physical activity to become a habit and to bring about a lifestyle change, children must be given the opportunity to participate in it daily [8].

Sallis et al. [13] argued that schools are the most costeffective public health resource in which to address inactivity and that physical education teachers are uniquely positioned to provide and promote the students' daily physical activity. Some authors believe that we need to capitalize more on the opportunity that Physical Education (P.E.) can provide, especially to school children, in reducing sedentary behavior and contributing to population health [8].

Students learn better when they are healthier [4]. Regardless of the competency of teachers or any other major academic measures put in place, educational progress will be profoundly limited if students' poor physical health leaves them without motivation to learn [4]. Health-related problems play a primary role in limiting the inspiration and ability to learn. If a sedentary lifestyle and lack of physical activity are cultivated in the school climate, then the students will be more likely to be unenthusiastic and to succumb to lifestyle diseases, which in turn will adversely affect learning [4]. Furthermore, children need to develop communication and social skills. The current preoccupation with electronic devices, to the exclusion of live engagement, puts at risk the holistic development of a child.

The need for increased research on student attitude to physical activity may be attributed in part to the expected influence attitude may have on future participation in physical activity among students [6]. There is evidence to suggest that students who exhibit negative feelings towards physical education and activity in school may 
refrain also from participating in physical activity outside of school [7]. According to Portman [11], promoting good attitudes towards physical activity and physical education is an important component in fostering an active lifestyle among our youth.

Additionally, the inclusion of research on students' attitudes has the potential to provide a more global view of student learning. The acquisition of knowledge about students' attitudes can help both teachers and students in the learning process. The possible influence of student attitude, with regard to physical activity, on the learning environment itself has not received much attention by sport pedagogy researchers [12]. More research is needed to fully explore any attitude-learning relationship in physical education.

Students come into the PE setting with different characteristics and dispositions. Students who possess an intense good feeling toward physical education affect the learning environment in a positive way [5]. It is a completely different situation when students come to physical education with strong negative feelings. Student attitude affects the ecology of the gymnasium, playfield and classroom [6].

\section{Methodology}

Both qualitative and quantitative data collection methods were used. This study was conducted with a sample of 21 form 3 students. These students were chosen because this would be their last academic year for participating in a compulsory physical education class. This form 3 class had a mixture of different body types, weights, ethnicities, religions, social and academic abilities, and personalities. Ten percent of the class received breakfast and lunch from the school feeding programme. All the students at this level had been exposed up to this point to physical activity only once every 6 days per week.

\subsection{Experimental Design}

Two survey instruments were used, one administered at the beginning and the other at the end of the programme. The first collected demographic data, information on physical activity practice, and the participants' views on the importance of physical education in promoting elements of health, fitness, and self-confidence. The second questionnaire collected the participants' perceptions of the different facets of the implemented programme and on the benefits they felt they had reaped from participation. In addition to the surveys, Observations and Field notes were used to gather additional information on the students, among which were punctuality, attendance, adherence to the rules, engagement in the activity, and general attitude (respect for authority, attention to instructions of the day, and satisfaction with daily activity).

This study was conducted over a 6-week period in the second term in the school year. Each student was given the opportunity to participate. Daily physical activity was conducted during the lunch period for 30 - 45 minutes per session. The programme involved three days of daily physical activity, which would result in energy expenditure. No student was involved in less than 540 minutes of physical activity over the 18 instructional sessions.

The session comprised of a warm up, followed by the main activity, then a cool down using planned exercises and games throughout. Prior to the start of the programme and at the end, discussion sessions were held with the students. This was so that they could understand what the programme involved and, afterwards, could get additional clarification on the rationales for different activities they had engaged in during the programme. The activities were designed to target 4 areas for physical improvementcardio-vascular endurance, muscular endurance, strength, and flexibility. All necessary resources and equipment were provided for the students. Clearly defined rules, with respect to noise levels, movement allowed, and time allocations for the exercises, were outlined at each session.

The unit on Fitness Training emphasized challenges, circuit activities, and games, using the existing equipment at the school. Students worked both in groups and individually to explore, observe and discover their hidden abilities. They were also encouraged to help their classmates increase their confidence levels. The Fitness Training programme was implemented for six weeks. The activities from weeks 1 to 3 were repeated in weeks 4 to 6 .

\subsubsection{Data Collection}

The demographics of the participants and the categorical responses given in the first and second survey are summarized in frequency distributions among the categories. These are tabulated. For some of these, wherever they could add clarity, bar charts were also used to capture some of the same distributions. Survey scale responses were summarized using statistics (means and standard deviations) for each item on the scale. In addition, a stacked horizontal bar chart was used for the scale on importance of physical education, which was administered to students in the initial survey. This allowed comparisons to be made between scale items. The summary statistics are listed for the biometric measurements (chest, hip, waist, weight, height, BMI, and fat $\%$ ) of the sample at the beginning and at the end of the programme.

The means of the items on the survey scale are ranked in decreasing order to discuss which benefits of physical education are perceived as most important by the students. Post-programme, the views of the students, captured as 'yes', 'no', 'don't know', on several aspects of the programme and its benefits are ranked, according to \% YES, in two separate tables, one for the positive and another for the negative items.

An ANOVA model, the General Linear Model Repeated Measures, using SPSS V.22 is used to estimate the significance of any changes, pre and post- programme, in hip, waist, weight, BMI, and fat $\%$ measurements. This model allows each student to act as his/her own control. Sex is used as a fixed independent factor so that the changes for boys and girls could be evaluated separately. Given the fact that maturation could have taken place during the period, age is used as a covariate. Chest and height measurements were not examined because these would be too confounded by maturation (chest) and/or had nothing to do with physical activity (height). 


\section{Results and Discussion}

This study sought to survey high school students' views after they participated in a daily structured physical activity programme for six weeks. It looked too at whether any significant impact on students' physical measurements of weight, hip, waist, body mass index, and \% fat could be detected. Field notes, maintained from observations of the students during the programme, were used to add insights into their enthusiasm for the activity, among other things.

\subsection{Summaries of Demographics and Categorical Responses}

Table 1. Frequency distributions of sample demographics and categorical survey responses

\begin{tabular}{|c|c|c|}
\hline Question & Response Category & Frequency $\%$ \\
\hline \multirow{2}{*}{ Sex } & Boys & 52 \\
\hline & Girls & 48 \\
\hline \multirow{3}{*}{$\begin{array}{c}\text { Do you like Physical } \\
\text { Education? }\end{array}$} & Yes & 100 \\
\hline & No & 0 \\
\hline & Don't know & 0 \\
\hline \multirow{7}{*}{$\begin{array}{l}\text { Why are you taking part in } \\
\text { this programme? }\end{array}$} & Increase fitness & 52 \\
\hline & Lose Weight & 43 \\
\hline & Just for fun & 43 \\
\hline & Improve self-esteem & 14 \\
\hline & Incentive Offered & 5 \\
\hline & Self-confidence & 5 \\
\hline & No Obvious reason & 0 \\
\hline \multirow{4}{*}{$\begin{array}{c}\text { How important is Physical } \\
\text { Activity to you? }\end{array}$} & Very Important & 24 \\
\hline & Important & 43 \\
\hline & Somewhat important & 29 \\
\hline & Not important & 4 \\
\hline \multirow{7}{*}{$\begin{array}{l}\text { How many days per week } \\
\text { at present do you } \\
\text { participate in } \\
\text { sports/physical activities? }\end{array}$} & 2 & 43 \\
\hline & 5 & 29 \\
\hline & 1 & 10 \\
\hline & 4 & 9 \\
\hline & 3 & 9 \\
\hline & 7 & 0 \\
\hline & 6 & 0 \\
\hline \multirow{5}{*}{$\begin{array}{l}\text { At present, how long do } \\
\text { you participate in } \\
\text { sports/physical activity } \\
\text { during schools' hours? }\end{array}$} & Less than 30 minutes & 38 \\
\hline & 30 minutes & 23 \\
\hline & 45 minutes & 14 \\
\hline & More than one hour & 14 \\
\hline & 1 hour & 9 \\
\hline \multirow{5}{*}{$\begin{array}{l}\text { How long do you spend in } \\
\text { sport/physical activity } \\
\text { outside of school hours? }\end{array}$} & More than one hour & 48 \\
\hline & 1 hour & 14 \\
\hline & 45 minutes & 9 \\
\hline & 30 minutes & 9 \\
\hline & Less than 30 minutes & 19 \\
\hline \multirow{2}{*}{$\begin{array}{l}\text { Do you think that physical } \\
\text { activity should be done } \\
\text { daily in schools? }\end{array}$} & Yes & 76 \\
\hline & No & 24 \\
\hline \multirow{6}{*}{$\begin{array}{l}\text { When do you think is the } \\
\text { best time within school } \\
\text { hours for students to } \\
\text { participate in a structured } \\
\text { physical activity session? }\end{array}$} & After lunch & 47 \\
\hline & During lunch & 42 \\
\hline & After morning break & 4 \\
\hline & After school & 4 \\
\hline & After morning assembly & 0 \\
\hline & Other & 0 \\
\hline \multirow{2}{*}{$\begin{array}{c}\text { Is it important to you to } \\
\text { maintain a healthy } \\
\text { lifestyle? }\end{array}$} & Yes & 100 \\
\hline & No & 0 \\
\hline \multirow{3}{*}{ Do you smoke? } & Yes & 5 \\
\hline & No & 90 \\
\hline & Sometimes & 5 \\
\hline \multirow{3}{*}{ Do you drink alcohol? } & Yes & 5 \\
\hline & No & 62 \\
\hline & Sometimes & 33 \\
\hline
\end{tabular}

The frequency $\%$ values are given in Table 1 . The sample was almost equally boys (52\%) and girls (48\%) between the ages of 13 to 15 years. All of them admitted to liking physical education and each had at least one obvious reason for participating, among the most frequent of which were better fitness (52\%), weight loss (43\%), and fun $(43 \%)$. Very few $(5 \%)$ were interested in the incentive offered or wanted to boost self-confidence $(5 \%)$.

Only $4 \%$ of the students in the sample viewed physical activity as being unimportant with many more (72\%) viewing it as either important or very important. Most (43\%) students participated in physical activity only twice a week but more than a quarter of them $(29 \%)$ said that they did so 5 times per week, No one participated in physical activity on 6 days or 7 days per week. The students $(76 \%)$ felt that physical activity should be done daily and in school. Most (61\%) students engaged in it for 30 minutes or less daily during school hours but, outside of school, almost the same amount $(62 \%)$ did so for 1 hour or more daily. Only $5 \%$ of students felt that the physical activity programme in which they had engaged should not be repeated, while 38\% suggested that it be carried out with all students and another $43 \%$ felt it could even be repeated with the same form 3 class. All students claimed to be maintaining a healthy lifestyle, with only $5 \%$ of them admitting to smoking and $5 \%$ admitting to drinking alcohol, although $33 \%$ more said they drank sometimes.

\subsection{Importance of Physical Education}

This issue was explored using an interval scale of 11 items, for which participants scored their views on the importance of each item, using from ' 0 ' (of no importance at all) to ' 5 ' (of maximum importance). The item means in ranked order and the corresponding standard deviations are given in Table 2. The mean gives the intensity of the perceived importance, averaged over all the participants, and the standard deviations give the level of consensus in their scores for each item. The higher the mean, the more important is the corresponding scale item and the lower the standard deviation the better is the consensus among the respondents in the scores awarded to that item.

Table 2. Means and standard deviations for the importance of Physical Education benefits

\begin{tabular}{|l|c|c|}
\hline $\begin{array}{l}\text { How Important do you think Physical } \\
\text { Activity is in promoting .......? }\end{array}$ & Mean & $\begin{array}{c}\text { Standard } \\
\text { Deviation }\end{array}$ \\
\hline disciplined behavior? & 4.52 & 0.68 \\
\hline a greater team spirits? & 4.48 & 0.81 \\
\hline physical health and fitness in an individual? & 4.43 & 0.81 \\
\hline motivation to improve one's physical health? & 4.38 & 0.74 \\
\hline good mental health? & 4.38 & 0.86 \\
\hline a reduced degree of obesity in a population. & 4.29 & 1.27 \\
\hline self-confidence? & 4.10 & 0.77 \\
\hline leadership development? & 3.95 & 0.97 \\
\hline intellectual development? & 3.86 & 0.91 \\
\hline socialization skills? & 3.14 & 1.39 \\
\hline emotional well-being? & 2.90 & 1.51 \\
\hline
\end{tabular}

The most important benefits promoted by physical education were perceived as disciplined behavior $($ mean $=4.52)$, team spirit $($ mean $=4.48)$, health and fitness $($ mean $=4.43)$, both physical $($ mean $=4.38)$ and mental health (mean $=4.38$ ) equally. Decreasing obesity in the population (mean $=4.29$ ) was only ranked 6 th. 
Emotional well-being was considered, on average, the least important benefit. However, given the large standard deviation, responses to this may have been very polarized.

A better view of the distributions among the categories of answers is given by the stacked horizontal bar graph in Figure 1. This shows that, whereas the items with the higher means are negatively skewed with most response scores between ' 3 ' and ' 5 ,' participants gave scores in every category of importance for emotional well- being with the most frequent score (38\%) being ' 4 '.

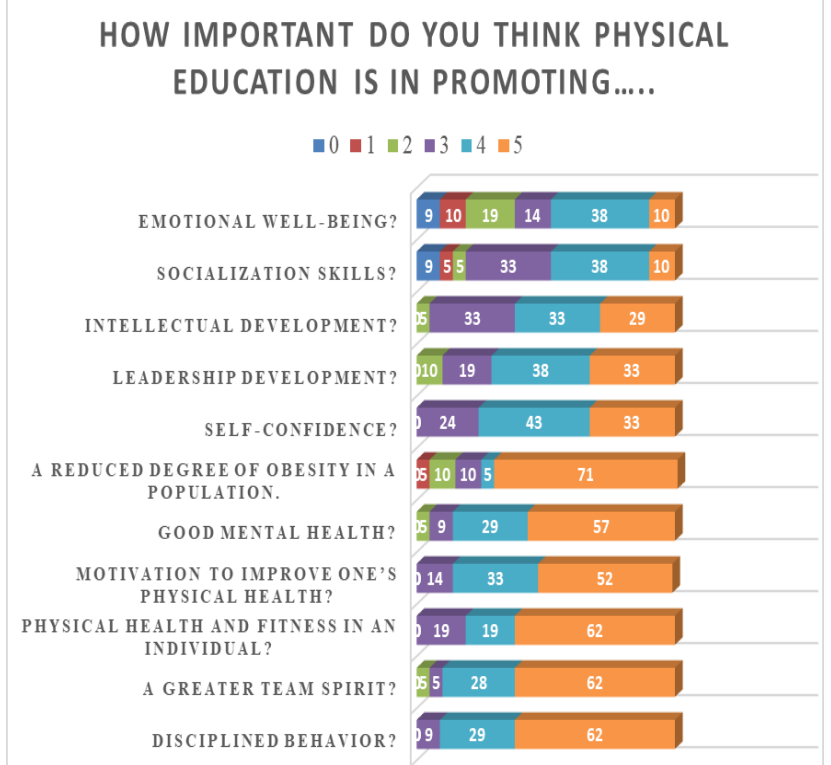

Figure 1. Frequency Distributions of the scores for items on the scale for the importance of Physical Education

\subsection{Impressions of the Programme}

Table 3. Positive and negative effects of the physical activity programme

\begin{tabular}{|c|l|c|c|c|}
\hline & This programme has & Yes & No & Don't know \\
\hline 1 & increased my self confidence & 95 & 5 & 0 \\
\hline 2 & $\begin{array}{l}\text { given me the urge to keep up } \\
\text { physical activity }\end{array}$ & 91 & 9 & 0 \\
\hline 3 & increased my self esteem & 91 & 9 & 0 \\
\hline 4 & helped me to get fitter & 86 & 5 & 8 \\
\hline 5 & made me want to stay healthy & 76 & 19 & 5 \\
\hline 6 & $\begin{array}{l}\text { helped me to sleep better each } \\
\text { night }\end{array}$ & 62 & 33 & 5 \\
\hline 7 & made me eat better & 52 & 29 & 19 \\
\hline 8 & helped me to lose weight & 48 & 52 & 0 \\
\hline 9 & helped me to lose inches & 48 & 38 & 14 \\
\hline 10 & $\begin{array}{l}\text { helped me to concentrate better } \\
\text { after lunch }\end{array}$ & 29 & 52 & 19 \\
\hline & This programme ... & Yes & No & Don't know \\
\hline 1 & made me sleepy in school & 52 & 48 & 0 \\
\hline 2 & made me tired in school & 48 & 52 & 0 \\
\hline 3 & made me put on weight & 43 & 57 & 0 \\
\hline 4 & has made me eat more & 29 & 62 & 9 \\
\hline 5 & was too long (months) & 0 & 100 & 0 \\
\hline 6 & $\begin{array}{l}\text { was conducted for too long each } \\
\text { day }\end{array}$ & 0 & 100 & 0 \\
\hline 7 & $\begin{array}{l}\text { was conducted at the wrong time } \\
\text { each day }\end{array}$ & 0 & 95 & 5 \\
\hline 8 & $\begin{array}{l}\text { was conducted for too many days } \\
\text { a week }\end{array}$ & 0 & 100 & 0 \\
\hline
\end{tabular}

Once the programme was completed, students were asked to rate its impact on them in terms of perceived feelings of well-being, improvements in physical fitness, and other possible changes in their biometrics. They were also asked about negative effects such as extra sleepiness or tiredness in class. The possible positive and negative impacts of the physical activity programme are separated and ranked, according to $\%$ Yes, in Table 3.

The biggest benefit ( $95 \%$ Yes) was seen to be the perceived increase in self-confidence that the students experienced. Also, highly rated were improved selfesteem (91\%), a greater urge to remain physically active (91\%), and better fitness (86\%). Not many (29\%) felt that their concentration improved after lunch. Among the negatives about half of the participants felt the programme made them sleepy $(52 \%)$ or tired $(48 \%)$ in school and made them put on weight (43\%). Only $29 \%$ felt it made them eat more. No one felt the programme was too long in total or each day or that it was conducted at the wrong time of day or for too many days a week.

\subsection{Observations captured in Field Notes}

Field notes were taken during the sessions. The students' comments were most informative. Overall, the students expressed a positive attitude when involved in the activities over the 6-week period. Some excerpts from their verbatim statements include "an interesting experience.... great way to explore different activities to understand the interrelated components of fitness" and "we are doing new things every other day that add to previous knowledge.... activities are interactive and fun!"

A checklist was used to observe the students. They were observed to be regular and punctual for each session, keeping up with the activity and attentive to directions and instructions, which were clearly communicated. Most of the time, they maintained a good relationship with each other. There was hardly any verbal dispute during the activity. The students came with a change of clothes daily and demonstrated respect for authority. The researchers observed the groups and found that many of the students enjoyed working with each other and carrying out the activity. There were only very few instances where students did not respond positively with each other and then, once guidance was provided, the groups settled and became more productive.

\subsection{Changes in Students' Physical Measurements}

In Table 4 are summary measurements for the students, obtained before and after the programme. There was no clear difference in any of the biometrics. However, it should be noted that maturation and eating habits during the 6 weeks of the programme could have confounded the results. In addition, while the students were measured by a nurse, some wore more clothes for their final measurement than for their initial measurement. Some boys wore two pairs of pants under their clothes and girls wore padded bras. Finally, muscle does weigh more than fat so during maturation, boys certainly could have lost fat and gained muscle. It is also possible that the duration of the programme was too short to observe any impact. 
Nevertheless, the results are still tested statistically, particularly to see if there was any interaction effect.

Statistical Data Analysis was carried out using SPSS V.22. The data was analyzed as a Repeated Measures General Linear Model with Sex as the independent variable, with each of WEIGHT, WAIST measurement, HIP measurement, \% Body Fat, or BMI as the dependent variable in separate analyses, and INITIAL HEIGHT and AGE as covariates. The rationale for the repeated measures approach is that everyone's readings, from before and after the programme, are compared in a design that is the highest form of control. What cannot be controlled, as noted before, is maturation during the programme so INITIAL HEIGHT and AGE are used as covariates to account for the confounding of the outcomes these may cause.

The analysis returns $p$ values for the impact on the dependent variable (WEIGHT, WAIST, HIP, \%BODY FAT, or BMI), caused by time (pre- to post- programme), by Sex and by the interactions of time with Sex, with Age, and with Height. There is no significant change in any of the individual metrics on completion of the programme. Only the interaction of time (pre-to post-programme) and Sex is significant for hip measurement $(p=0.000)$. Plots of the values, separated for boys and girls, show trends over time (pre- to post-programme) for the dependent variable for each group. The weight change from before to after is small and the pattern is the same for girls and boys (Figure 2). Waist size trends downwards for girls but upwards for boys and the plots cross, signifying that this interaction should be significant, except that there may be too much variance to pick it up in the test itself (Figure 3). For hip measurement, the mean value for girls is trending upwards but that for boys decreased slightly, causing the interaction effect to be significant (Figure 4). This interaction effect tests for significance of the difference in pre-post measurement gaps for boys and girls. BMI and \% Fat are both trending downwards for boys and for girls so that maybe with a longer duration, the decrease with activity would have been significant (Figure 5 and Figure 6). Note the pattern is the same for boys and girls for both biometrics.

Table 4. Sample Biometrics -pre- and post- Physical Activity Programme

\begin{tabular}{|c|c|c|c|c|c|c|c|c|}
\hline \multirow{2}{*}{ Biometric Measure } & \multicolumn{2}{|c|}{ Minimum } & \multicolumn{2}{|c|}{ Maximum } & \multicolumn{2}{|c|}{ Mean } & \multicolumn{2}{|c|}{ Std. Deviation } \\
\hline & Initial & Final & Initial & Final & Initial & Final & Initial & Final \\
\hline Age (years) & \multicolumn{2}{|c|}{13.0} & \multicolumn{2}{|c|}{15.0} & \multicolumn{2}{|c|}{14.3} & \multicolumn{2}{|c|}{0.56} \\
\hline Weight (kg) & 36.1 & 37.7 & 95.2 & 96.7 & 61.4 & 61.6 & 17.6 & 17.5 \\
\hline Height $(\mathrm{cm})$ & 158.0 & 158.0 & 177.0 & 179.0 & 166.4 & 167.6 & 5.2 & 6.0 \\
\hline Chest $(\mathrm{cm})$ & 27.5 & 20.0 & 43.0 & 43.0 & 33.9 & 33.2 & 4.8 & 5.6 \\
\hline Hip $(\mathrm{cm})$ & 31.5 & 32.0 & 48.0 & 50.0 & 38.5 & 38.8 & 5.1 & 5.6 \\
\hline Waist $(\mathrm{cm})$ & 23.0 & 24.0 & 39.0 & 40.5 & 30.6 & 30.3 & 5.1 & 4.8 \\
\hline$\%$ Body Fat & 6.0 & 4.00 & 41.0 & 40.0 & 22.5 & 20.8 & 11.3 & 11.3 \\
\hline BMI & 14.0 & 10.0 & 33.0 & 34.0 & 21.9 & 21.2 & 5.7 & 6.2 \\
\hline
\end{tabular}

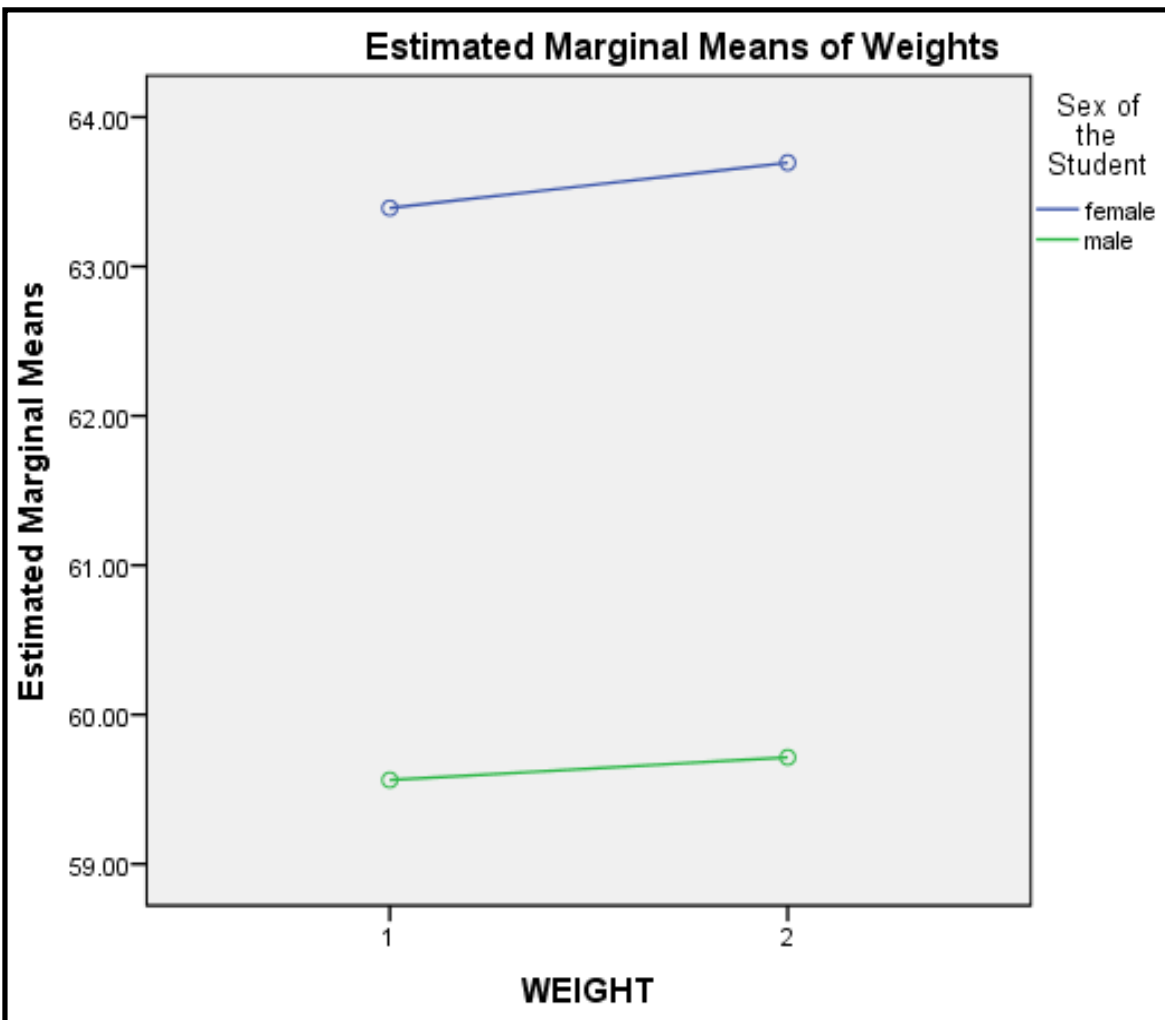

Covariates appearing in the model are evaluated at the following values: Age of the student (years) = 14.2857 , Initial height $=166.3810$ 


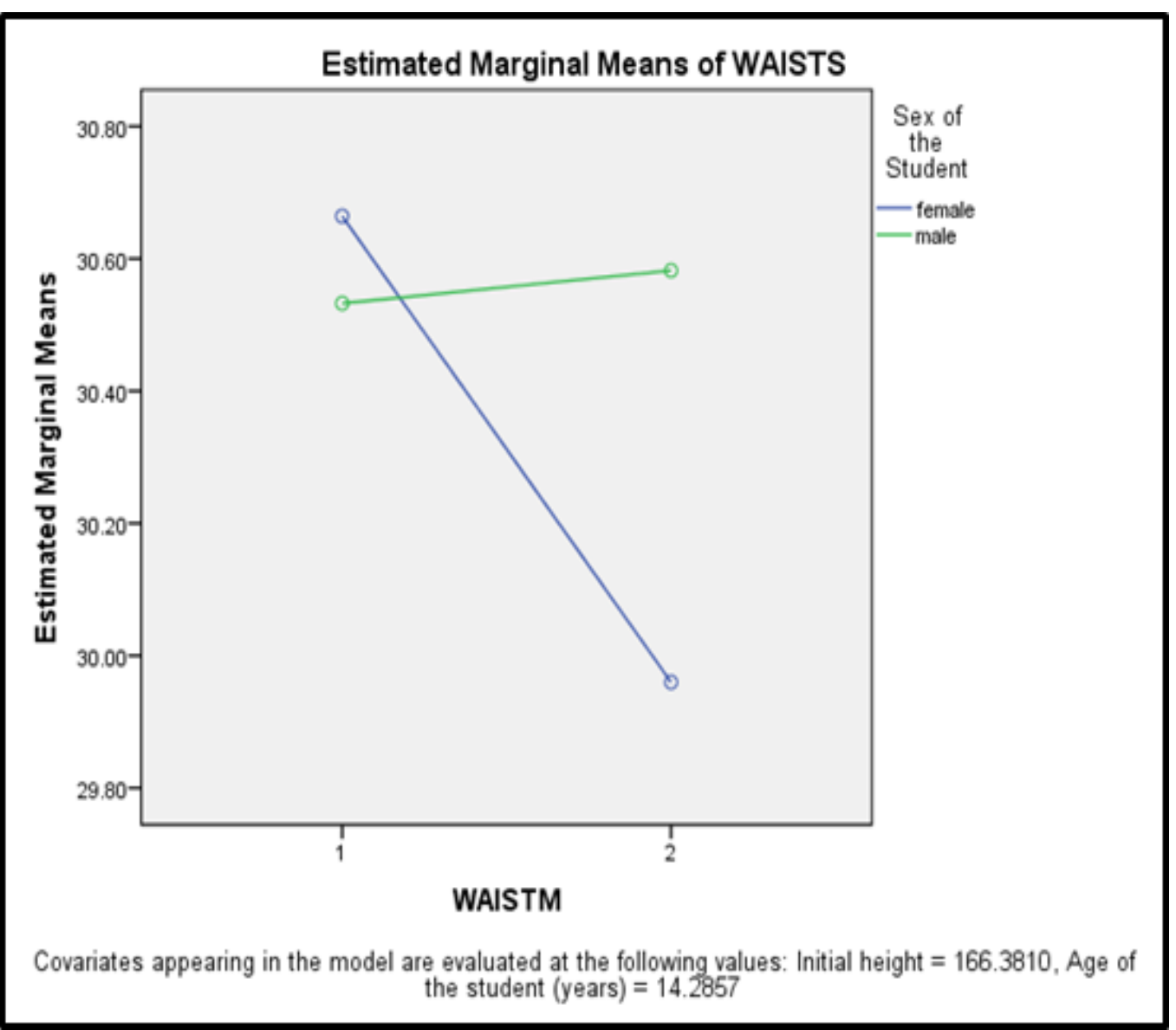

Figure 3. Change in mean waist size from before to after the programme

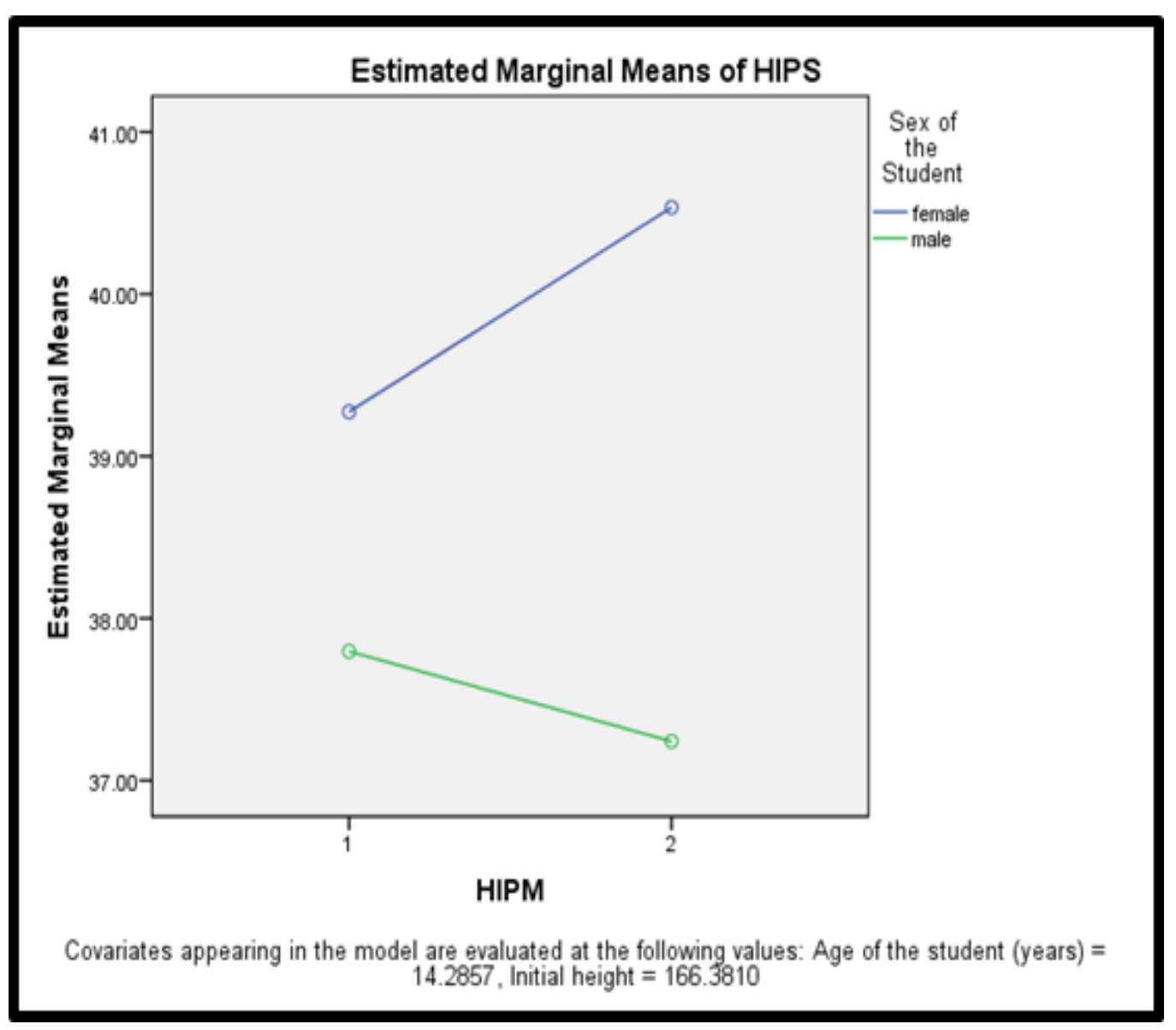

Figure 4. Change in mean hip size from before to after the programme 


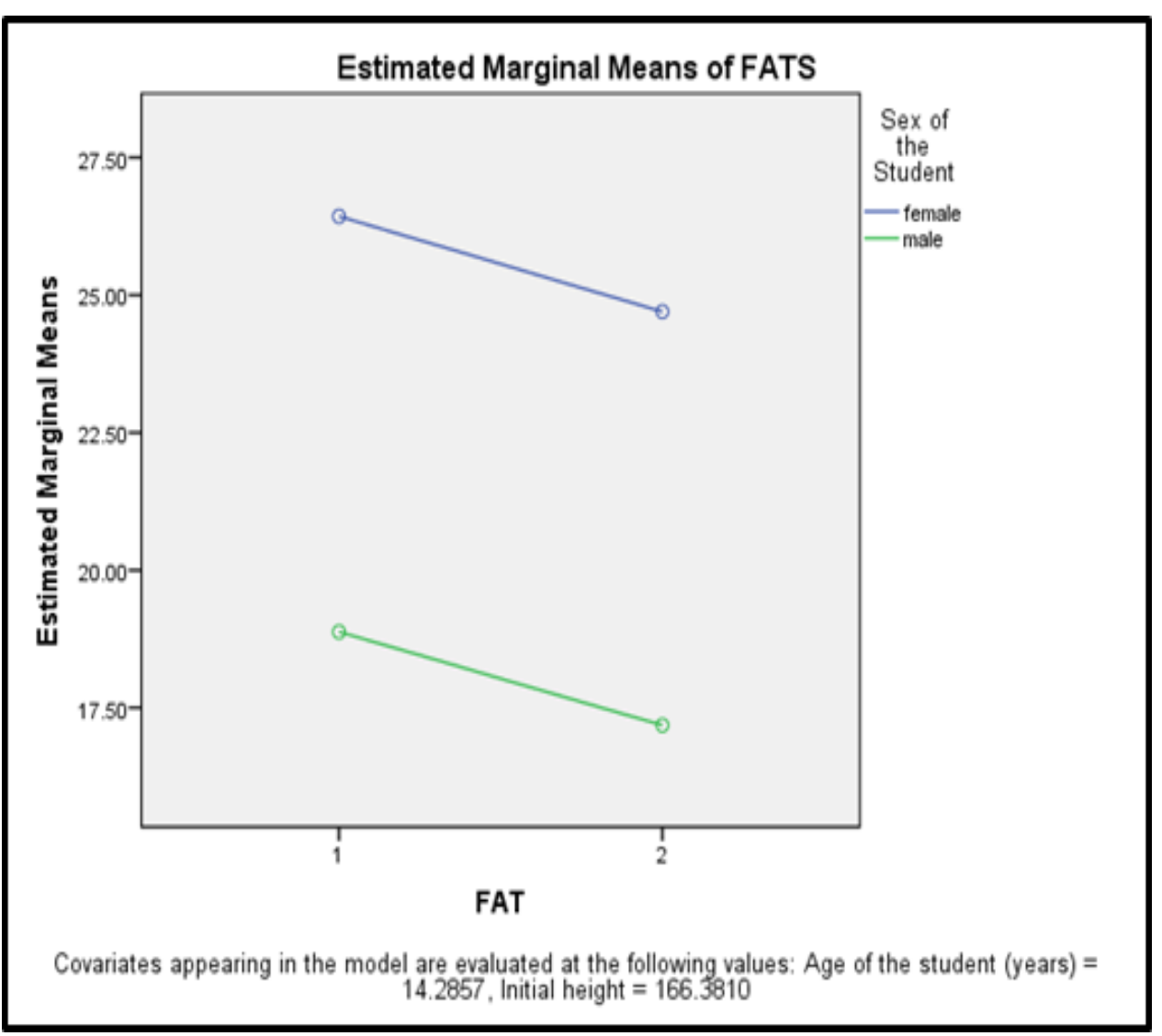

Figure 5. Change in mean $\%$ Fat from before to after programme

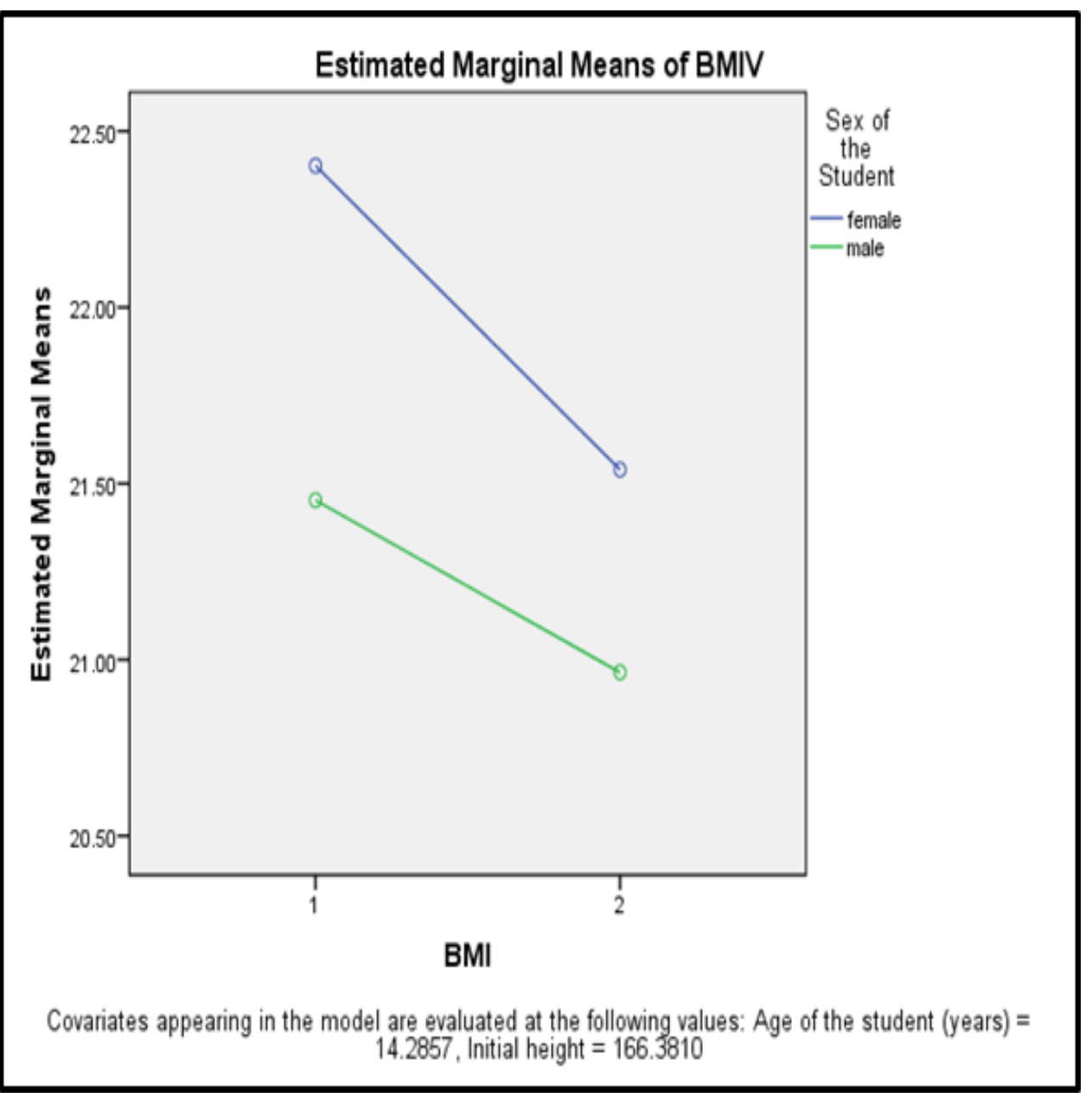

Figure 6. Change in BMI from before to after the programme 


\section{Conclusion}

The data collected and analyzed indicated that the students held positive attitudes about the programme and its effects on several aspects of their general well-being. However, there were no statistically significant changes on their body weights, BMI, \% Fat, waist or hip measurements. This is not unexpected since there are several unknown confounders of this effect, including maturation and diet maintained during the programme. There is also the possibility that the duration was too short. This is borne out by the downward (though nonsignificant) trends seen in the mean waist (girls) and hip (boys) measurements, BMI, and \%Fat, even though the mean weights were unchanged for both sexes. It is supported too by the observations of other researchers that the effects of physical activity alone on reductions in body weight may be somewhat modest but can be more effective on a long-term basis [15].

Students were committed to the programme which resulted in increased fitness levels, both according to their own perceptions and based on the researchers' observations that students took fewer breaks as the programme progressed. Most $(78 \%)$ indicated that the programme made them want to stay healthy and, hopefully, this will create a desire in them to continue to stay physically active, allowing them to manage their weight and to lead healthy lifestyles. Students indicated that the programme should be done daily $(76 \%)$, done during school hours (93\%), and is worth repeating (95\%). All the students felt that it was important to maintain a healthy lifestyle.

During the six weeks of the programme, the culture of the school environment during the lunch period was different because students and even some teachers were involved in structured physical activity. The students seemed devoted to the programme, willing to switch their interest away from their hand- held electronic devices to physical activity. The whole school was involved one way or the other, if not observing then participating in the programme. There were members of staff and administration, also participating in the programme, who indicated they have no time to exercise but wanted to lose weight and relieve stress. There were other teachers who did not participate but encouraged the students from other groups, such as the young leaders, to get involved in the programme. During the six weeks, there were no issues of petty squabbles and the administration workload was reduced because of fewer disciplinary issues, with most students gravitating to the area where the programme was held.

This study registered positive impacts on a sample of students, both in terms of their fitness and their attitudes, from participation in a daily programme of structured physical activity. There was no statistically significant evidence from this brief programme to support a claim of average weight loss for the sample. Possibly, though, with longer duration a more pronounced effect could be observed to reinforce the argument that frequent use of daily activities in the Physical Education practical classes could control weight gain. Still, there is enough support from this study for a conclusion that physical activity, recognized as a relatively inexpensive path, could affect attitudinal change in children. With enough exposure and encouragement, this could lead to lifestyle changes and possibly better weight management and general health. Note, however, that the confounding effects of maturation and diet will present problems in studies with children.

Future practical efforts will involve formalizing and adding to the Daily Structured Physical Activity programme developed for and used in this study and exploring opportunities for repeating the study at the same school with other forms, while introducing the programme to colleagues at other schools so that they could implement it. A proposal of work will be submitted to the Ministry of Education. We are looking into possible sponsorship which could provide incentives for encouraging student and staff participation in daily structured physical activity programmes.

\section{References}

[1] "Physical activity improves quality of life," American Heart Association, Mar. 2015. [Online] Available:

http://www.heart.org/HEARTORG/HealthyLiving/PhysicalActivit y/FitnessBasics/Physical-activity-improves-quality-oflife_UCM_307977_Article.jsp\#.WDSCs7szVlY. [Accessed May $\left.2^{\text {nd }}, 2015\right]$.

[2] Bailey, R., Cope, E., and Parnell, D. "Realising the benefits of Sports and Physical Activity: The Human Capital Model," Retos, 28, 147-154. 2015.

[3] Bandura, A., "Health promotion from the perspective of social cognitive theory," Psychology \& Health, 13(4), 623-649, Jan.1998.

[4] Basch, C. E. "Healthier students are better learners: High-quality, strategically planned, and effectively coordinated school Health Program must be a fundamental mission of schools to help close the Achievement Gap," Journal of School Health, 81(10), 650662, Oct. 2011.

[5] Brophy, J., and Good, T. "Teacher behavior and student achievement," Handbook of research on teaching $3^{\text {rd }}$ edition, M. C. Wittrock (Ed.), McMillan, New York, 1986, 328-375.

[6] Carlson, T.B."Why students hate, tolerate, or love gym: A study of attitude formation and associated behaviors in physical education," Journal of Teaching in Physical Education, 34 (3), 467-477. 2015.

[7] Ennis, C.D. 'Students' experiences in sport-based physical education: [More than] apologies are necessary," Quest, 48, 453-456, 1996.

[8] Mc Kenzie, T. L., and Lounsbery, M. A. "Physical Education teacher effectiveness in a Public Health context," Research Quarterly for Exercise and Sport, 84 (4), 419-430, 2013.

[9] "NIH study finds leisure-time physical activity extends life expectancy as much as 4.5 years," National Cancer Institute, Nov. 2012. [Online] Available: https://www.cancer.gov/newsevents/press-releases/2012/PhysicalActivityLifeExpectancy. [Accessed May 20, 2017].

[10] Nevill, A. M., Tsiotra, G., Tsimeas, P., and Koutedakis, Y. "Allometric associations between body size, shape, and physical performance," Pediatric Exercise Science, 21 (2), 220-232, 2009.

[11] Portman, P. "Who is having fun in physical education class? Experiences of six-grade students in elementary and middle schools," Journal of Teaching in Physical Education, 34 (3), 445-461, 2015.

[12] Rikard, G. "The relationship of teachers' task refinement and feedback to students' practice success," Journal of Teaching in Physical Education, 31 (4), 349-357, 2012.

[13] Sallis, J., Mc Kenzie, T., Beets, M., Beighle, A., Erwin, H., and Lee, S. "Physical education's role in public health," Research Quarterly for Exercise and Sport, 83 (1), 125-135, 2012.

[14] Thompson, P.D., Buchner, Piña, I.L., Balady, J.G., Williams, M.A.; Marcus, B., ... "Exercise and physical activity in the prevention and treatment of atherosclerotic cardiovascular disease," Circulation, 107 (24), 3109-3116, August 2003. 
[15] Wing, R.R., Venditti, E., Jakicic, J.M., Polley, B. A., and Lang, W. "Lifestyle intervention in overweight individuals with a family history of diabetes," Diabetes Care, 21 (3), 350-359, March 1998.

[16] World Health Organization, "The Ministry of Health targets its youth in the fight against CNCDs," Government of the Republic of Trinidad and Tobago Ministry of Health, May 2011.[Online] Available: http://www.health.gov.tt/news/newsitem.aspx?id=247. [Accessed Sept.21 $\left.{ }^{\text {st }}, 2018\right]$. 